\title{
A escrita de resumos no quadro dos letramentos acadêmicos de estudantes de graduação
}

\section{The Writing of Abstracts in the Framework of Undergraduate Students' Academic Literacies}

\author{
Bárbara Olímpia Ramos de Melo* \\ *Universidade Estadual do Piauí (UESPI), Teresina, Piauí / Brasil \\ barbaraolimpiam@gmail.com \\ https://orcid.org/0000-0001-6523-8835 \\ Benedito Gomes Bezerra** \\ **Universidade Católica de Pernambuco (UNICAP), Recife, Pernambuco / Brasil \\ beneditobezerra@gmail.com \\ https://orcid.org/0000-0002-7382-0937
}

\begin{abstract}
RESUMO: A produção escrita de resumos de trabalhos científicos integra práticas de letramento complexas e diversificadas, das quais os estudantes são chamados a participar desde a graduação universitária. Neste estudo, sob a perspectiva dos estudos de letramento e de teorias de gênero aplicadas à escrita acadêmica, analisamos 32 exemplares de resumos, observando sua configuração retórica como um dos elementos indicadores dos letramentos acadêmicos de estudantes de graduação. Observações adicionais sobre os letramentos acadêmicos dos autores foram construídas a partir da aplicação de um questionário enviado por e-mail. Os resultados sugerem certa flexibilidade tanto da parte dos alunos como dos participantes experimentados da comunidade discursiva em lidar com as convenções que regem a construção do resumo acadêmico.
\end{abstract}

PALAVRAS-CHAVE: letramentos acadêmicos; resumos; organização retórica.

ABSTRACT: The writing of scientific works' abstracts integrates complex and diversified literacy practices, in which students are invited to participate since their undergraduate courses. In this study, from the perspective of literacy studies and genre theories applied to academic writing, we analyzed 32 exemplars of abstracts, observing their rhetorical configuration as one of the indicators of undergraduate students' academic literacies. Additional observations on the authors' academic literacies were constructed through a questionnaire sent to them by email. The results suggest a certain flexibility both on the part of the students and of the experienced participants of the discourse community in 
dealing with the conventions that govern the construction of the academic abstracts.

KEYWORDS: academic literacies; abstracts; rhetorical organization.

\section{Introdução}

As práticas de letramento das quais os estudantes são chamados a participar desde a graduação universitária são diversificadas e complexas, marcadas pela exigência de atender simultaneamente a convenções e a expectativas de "novidade", no dizer de Berkenkotter e Huckin (1995). No quadro mais amplo dos letramentos acadêmicos, a escrita de resumos de trabalhos científicos se realiza em uma relação dinâmica entre a produção de textos com suas convenções linguísticas e discursivas e a inserção em uma comunidade discursiva com suas normas explícitas ou tácitas para a admissão de novos participantes.

O termo "resumo", quando usado para designar um gênero, esconde uma paradoxal complexidade: por um lado, uma aparente clareza e inequivocidade, afinal, o nome do gênero alude à ação comunicativa que ele realiza, qual seja a de resumir um texto conservando ou apresentando seu conteúdo principal. Por outro lado, o resumo, como designação de gênero, demanda especificação, ou seja, é preciso dizer de que espécie de resumo se trata. Em outras palavras, o resumo não é um gênero único e singular, mas uma "colônia de gêneros", conceito desenvolvido por Bhatia $(2004,2009)$ e aplicado, por exemplo, nos estudos de Bezerra (2007, 2012a, 2017), Pimentel (2014) e Oliveira (2017).

Dentre os membros da colônia de gêneros de resumo que circulam no meio acadêmico, podemos citar os resumos de trabalhos de conclusão de cursos de graduação (TCC), monografias ou TCC de especialização, dissertações de mestrado, teses de doutorado e artigos científicos, além dos resumos de comunicações orais ou de pôsteres acadêmicos, submetidos a eventos científicos e geralmente vinculados a pesquisas acadêmicas finalizadas ou em andamento. Os exemplares de resumos que foram objeto de análise neste trabalho são resultantes de pesquisas concluídas em um programa institucional de iniciação científica (IC) em cursos de graduação.

Nosso objetivo neste trabalho é examinar o resumo de pesquisas de IC como um gênero marcado por especificidades contextuais bastante claras, que se refletem em aspectos da organização e distribuição das informações 
nos textos produzidos com o propósito de submissão ao Simpósio de Iniciação Científica da universidade mantenedora do programa de IC. Tais especificidades contextuais implicam articular os dados dos resumos sob análise a uma discussão das práticas de leitura e escrita vinculadas ao processo de letramento acadêmico dos autores dos textos, de modo a verificar como os alunos apreendem as orientações contidas nos editais de inscrição do evento para elaboração do resumo e de que forma tal apreensão (uptakee $)^{1}$ manifesta-se materialmente na construção dos exemplares de resumos.

Em vista de seu objetivo, o artigo se organizará em cinco tópicos além desta introdução e das considerações finais. No primeiro, discutimos os gêneros acadêmicos no quadro mais amplo dos letramentos. No segundo, tratamos do resumo como um gênero inserido em uma colônia e em uma cadeia de gêneros, resenhando os principais estudos sobre o tema, do ponto de vista de sua configuração retórica. No terceiro, contextualizamos o resumo nas práticas de letramento do evento de iniciação científica. Nos dois tópicos seguintes, apresentamos respectivamente os procedimentos metodológicos que orientaram o estudo e os resultados decorrentes da análise textual e das respostas de egressos do programa de IC a um questionário enviado por e-mail.

\section{A produção escrita de gêneros na perspectiva dos letramentos acadêmicos}

A compreensão do resumo, como a de qualquer outro gênero, não é possível apenas por meio da análise textual ou por qualquer outro procedimento que consista em tratá-lo como objeto estanque. No quadro mais amplo da escrita científica, o resumo é expressão de práticas de letramento típicas do contexto acadêmico, de modo que o tratamos aqui em uma relação estreita, do ponto de vista teórico, entre teorias de letramento e teorias de gênero. ${ }^{2}$ Assim, encontramos na perspectiva dos Novos Estudos

\footnotetext{
${ }^{1}$ Segundo Bawarshi e Reiff (2013, p. 112), apreensão ou uptake designa a "habilidade de saber negociar os gêneros e como aplicar e transformar estratégias de gênero (regras do jogo) em práticas textuais (performance real)".

${ }^{2}$ O trabalho desenvolvido por David Russell, Mary Lea, Jan Parker, Brian Street e Tiane Donahue (RUSSELL et al., 2009) segue parcialmente nessa direção, ao discutir gênero no campo dos Letramentos Acadêmicos (Academic Literacies - ACLITS) e da Escrita Através do Currículo (Writing Across the Curriculum - WAC).
} 
de Letramento (STREET, 2010, 2012, 2014) o suporte teórico adequado para o tratamento da escrita científica concretizada em gêneros. Nessa perspectiva, Lea e Street $(1998,2006)$ descrevem três abordagens para a compreensão do processo de inserção do estudante nas práticas de escrita e de leitura no contexto acadêmico: o modelo de habilidades de estudo, de socialização acadêmica e dos letramentos acadêmicos.

Resumidamente, o modelo de habilidades de estudo concebe a escrita e a leitura na universidade como resultado de habilidades individuais e cognitivas, de validade geral para qualquer situação comunicativa, de caráter técnico e predominantemente linguístico. Essas habilidades seriam, portanto, transferíveis da educação básica para o ensino superior, por exemplo.

O modelo de socialização acadêmica consiste na aculturação do estudante nos gêneros e discursos característicos de cada área, sugerindo que basta ao aluno adquirir os modos de falar, escrever e pensar característicos dos participantes experientes da comunidade discursiva em questão. A escrita é concebida, assim, como um meio transparente e estável de representação do conhecimento em dada área disciplinar, vista como homogênea. A terceira abordagem, o modelo dos letramentos acadêmicos, sem desprezar os aspectos positivos destacados pelos anteriores, se interessa pela "produção de sentido, identidade, poder e autoridade" e procura enfatizar "a natureza institucional do que 'conta' como conhecimento em qualquer contexto acadêmico específico" (LEA; STREET, 2006, p. 368). ${ }^{3}$

Essa abordagem dos letramentos acadêmicos, sensível aos processos sociais que envolvem as práticas de escrita na universidade, à situação comunicativa em que os estudantes se encontram e às relações institucionais e de poder específicas do ambiente acadêmico, nos parece a mais adequada para o estudo da produção de gêneros acadêmicos como o resumo por estudantes de graduação, conforme proposto neste trabalho.

Quanto aos gêneros, assumimos a concepção de Miller (2012, p. 34) de gênero como ação social e retórica tipificada "em situações recorrentes", expandida em várias direções pelo tão frequentemente citado parágrafo de Bazerman (2011, p. 23):

\footnotetext{
${ }^{3}$ Uma apresentação mais detalhada desses modelos se encontra em Bezerra (2012b) e Bezerra e Lêdo (2018).
} 
Gêneros não são apenas formas. Gêneros são formas de vida, modos de ser. São frames para a ação social. São ambientes para a aprendizagem. São os lugares onde o sentido é construído. Os gêneros moldam os pensamentos que formamos e as comunicações através das quais interagimos. Gêneros são os lugares familiares para onde nos dirigimos para criar ações comunicativas inteligíveis uns com os outros e são os modelos que utilizamos para explorar o não familiar.

Entendemos que o aluno de IC, diante da tarefa de produzir um resumo para o evento institucional do programa, precisa se situar nesse lugar que é o gênero para produzir sentidos de maneira aceitável pela comunidade acadêmica. Por outro lado, as convenções do gênero deverão funcionar como as "placas de trânsito" (guideposts, no original, foi traduzido na obra em português como "modelos") que orientarão o estudante no caminho para esse lugar de produção de sentidos. Esse é um importante aspecto dos processos de letramento acadêmico do aluno.

Considerando os pontos em comum entre as diversas abordagens para o estudo dos gêneros, destacamos ainda a contribuição de Swales (1990), em sua busca por um construto teórico-metodológico que permitisse a análise do texto em contexto, superando a redução da análise de gênero a um estudo de estruturas e elementos linguísticos. Para Swales (1990, p. 58), o gênero "consiste em uma classe de eventos comunicativos, cujos membros compartilham um conjunto de propósitos comunicativos". Nessa definição, o autor atribui forte centralidade aos propósitos comunicativos, entendidos como "a razão fundamental" que, em última instância, "molda a estrutura esquemática do discurso e tanto influencia como restringe escolhas de conteúdo e estilo". Além desse impacto dos propósitos comunicativos sobre a escrita do texto, o autor assinala que eles também são "o critério privilegiado" responsável por manter a relação necessária entre o gênero e uma "ação retórica comparável” (SWALES, 1990, p. 58).

Importante ressaltar que, em obra posterior, Swales (2004, p. 61) se refere a essa definição de gênero como "ousada", em especial pelo papel atribuído aos propósitos comunicativos. De acordo com o autor, uma marca das definições de gênero é o caráter metafórico, assim, diferentes metáforas para gênero podem oferecer contribuições para a pesquisa em conformidade com diferentes circunstâncias de análise. A propósito, Swales (2004) menciona seis metáforas, resumidas no esquema a seguir: 
FIGURA 1 - Metáforas para gênero

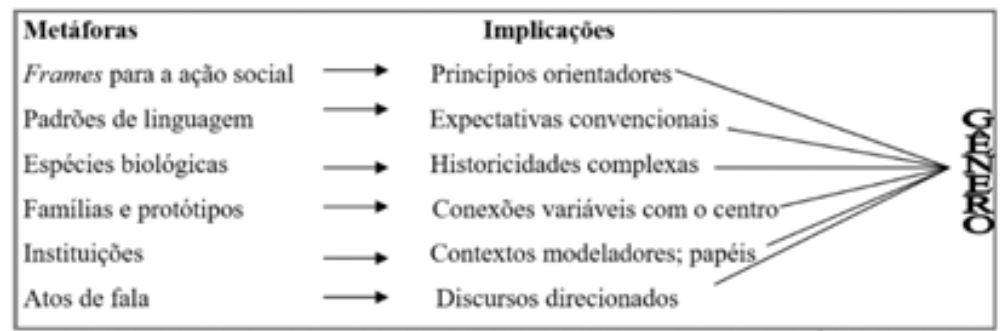

Fonte: Swales (2004, p. 68).

Ao destacar a primeira metáfora, Swales se aproxima da posição de Bazerman (2011) sobre o gênero como enquadre (frame) para a ação social. Para Swales (2004, p. 61), o gênero fornece a "orientação inicial”, mas não garante que a "ação retórica efetiva realmente será realizada". Enfim, não se trata de simplesmente atender a um conjunto de expectativas da comunidade acadêmica, pois a escrita acadêmica está sempre envolvida em um complexo jogo de linguagem que inclui questões de hierarquia, de poder e de construção de identidades, conforme a perspectiva dos letramentos acadêmicos que expusemos anteriormente.

Assim, coerentemente com as concepções de letramento e de gênero aqui expostas, neste estudo, aspectos mais linguísticos e estruturais como a análise de movimentos retóricos e de elementos léxico-gramaticais, baseada em Swales (1990), não têm sua finalidade em si mesmos, mas são tomados como aspectos funcionais sinalizados pela organização do texto. Os movimentos retóricos, particularmente, são estratégias utilizadas pelo escritor para atingir determinados objetivos, além de evidenciar o atendimento às expectativas da comunidade discursiva. Swales (2004, p. 228) alerta que, embora os movimentos retóricos muitas vezes sejam sinalizados linguisticamente (por exemplo, usar o termo "objetivo" ou formas do verbo "objetivar" para indicar os objetivos do trabalho), um movimento retórico (move) é "uma unidade discursiva ou retórica que realiza uma função comunicativa coerente no discurso falado ou escrito”. Não é possível, portanto, reduzir os movimentos retóricos a unidades gramaticais como oração, período ou parágrafo. 


\section{$3 \mathrm{O}$ gênero resumo na comunidade acadêmica}

Com o termo "resumo acadêmico", nos referimos a uma variedade (colônia) de resumos de trabalhos acadêmicos, produzidos para fins de publicação (resumos de artigos científicos, de comunicação oral, trabalhos completos em anais de eventos científicos etc.) ou para fins de conclusão de cursos de graduação e pós-graduação (resumos de TCC, dissertação, tese). Não nos referimos, portanto, a resumos como atividade escolar de sumarização de textos para fins de compreensão ou avaliação. O resumo de relatório final de Iniciação Científica, objeto deste estudo, é uma variedade de resumo para eventos, uma vez que se trata de trabalho a ser apresentado na jornada de IC da instituição de origem do programa de onde provieram os textos.

Assim como outros gêneros da escrita acadêmica, o resumo acadêmico tem sido objeto de importantes pesquisas no contexto brasileiro, dentre as quais mencionamos Biasi-Rodrigues (1998, 2009), Araújo (1999) e, mais recentemente, Oliveira (2017). As motivações para tais estudos têm sido principalmente compreender como se dá a organização e a condução das informações no gênero, relacionando-as aos respectivos propósitos comunicativos, assim como discutir a relação entre o texto e os fatores contextuais que condicionam sua produção.

Referindo-se ao resumo de comunicação oral em eventos, Oliveira (2017) argumenta que se trata de um gênero acadêmico "menor" em termos de extensão e "autônomo" no que tange à circulação. O resumo de comunicação "é autônomo porque circula isoladamente do gênero que resume, ao contrário de outros resumos diários que circulam juntamente com o texto maior do qual fazem parte" (OLIVEIRA, 2017, p. 15). Portanto, segundo o autor, uma peculiaridade do resumo de comunicação é que ele "precede o texto maior, não é uma redução do texto-fonte".

Compreendemos que o resumo de comunicação oral "precede" o texto-fonte em dois sentidos possíveis: primeiro, porque é submetido ao evento de forma independente, autônoma, desacompanhado do "texto maior"; segundo, porque artigos resultantes de comunicações orais frequentemente são produzidos após a realização do evento e, consequentemente, após a produção do resumo e da comunicação correspondente. Os anais que publicam tais trabalhos completos com seus respectivos resumos também costumam ser finalizados posteriormente ao evento. Essa singularidade apontada por Oliveira (2017) é importante para 
nosso estudo, pois os resumos que compõem o corpus desta pesquisa também apresentam a característica de autonomia e têm como texto-fonte um gênero maior, o relatório final da pesquisa.

Sem prejuízo para o fato de integrar uma colônia de gêneros, neste estudo, para os fins de nossa análise, o resumo de pesquisas de IC também é visto como integrante do que Swales (2004) chamou de "cadeia de gêneros", ou seja, como parte constitutiva de uma situação comunicativa em que certos gêneros se relacionam em sequência, um sucedendo o outro, inclusive cronologicamente, em sua realização. Conforme Bezerra (2017, p. 59), "o conceito de cadeia de gêneros permite o agrupamento de gêneros intimamente relacionados e que se relacionam numa ordem cronológica ditada por procedimentos bastante estereotipados". Ainda na perspectiva do autor, falando de conceitos que categorizam as relações entre os gêneros, o fundamental

[...] não é o conceito teórico que se adota, mas a perspectiva de que os gêneros são mais bem compreendidos se encarados como se encontram no mundo real, e não abstraídos como objeto de preocupação pedagógica. No mundo real, os gêneros são entidades complexas, dinâmicas e inter-relacionadas de diversas formas. (BEZERRA, 2017, p. 61)

A cadeia em que o nosso objeto de estudo está inserido pode ser descrita, embora parcialmente e considerando o objeto de estudo, da seguinte forma: edital para seleção de projetos, projeto de pesquisa submetido pelo professor, parecer do comitê interno de pesquisa, relatórios parcial e final da pesquisa, edital de inscrição do simpósio de iniciação científica, resumo, carta de aceite, anais, banner e/ou slides com o texto a ser apresentado durante o evento e certificado de participação.

Do ponto de vista da abordagem de gênero, uma das descrições fundamentais do resumo foi o estudo que resultou na tese de doutoramento de Biasi-Rodrigues (1998). No trabalho, a pesquisadora apresenta a descrição retórica de resumos de dissertações de mestrado da área de Linguística, tomando como base a análise de movimentos retóricos proposta por Swales (1990) na forma do Modelo CARS, ${ }^{4}$ resultante de pesquisa do autor sobre a organização de introduções de artigos científicos. Biasi-Rodrigues (1998),

${ }^{4} \mathrm{O}$ acrônimo CARS significa Create a Research Space (criar um espaço de pesquisa). 
após a análise de um corpus de 134 resumos, constata que, apesar da relativa flexibilidade e consequente variação na construção de textos no gênero, é possível inferir dos dados um modelo de organização retórica do resumo, composto por cinco unidades ou movimentos retóricos.

FIGURA 2 - Organização retórica de resumos de dissertação em Linguística

\begin{tabular}{|c|c|}
\hline \multicolumn{2}{|l|}{ Unidade retórica 1 - Apresentação da pesquisa } \\
\hline Subunidade 1A - Expondo o tópico principal & e/ou \\
\hline Subunidade IB - Apresentando o(s) objetivo(s) & e/ou \\
\hline \multicolumn{2}{|l|}{ Subunidade 2 - Apresentando a(s) hipótese(s) } \\
\hline \multicolumn{2}{|l|}{ Unidade retórica 2 - Contextualizaçâo đa pesquisa } \\
\hline Subunidade 1 - Indicando área(s) de conhecimento & e/ou \\
\hline Subunidade 2 - Citando pesquisas/teorias/modelos anteriores & e/ou \\
\hline \multicolumn{2}{|l|}{ Subunidade 3 - Apresentando um problema } \\
\hline \multicolumn{2}{|l|}{ Unidade retórica 3 - Apresentação da metodologia } \\
\hline Subunidade 1A - Descrevendo procedimentos gerais & e/ou \\
\hline Subunidade 1B - Relacionando variàveis/fatores de controle & e/ou \\
\hline \multicolumn{2}{|l|}{ Subunidade 2 - Citando/descrevendo o(s) método(s) } \\
\hline \multicolumn{2}{|l|}{ Unidade retórica 4 -Sumarizaçâo dos resultados } \\
\hline Subunidade 1A - Apresentando fato(s)/achado(s) & e/ou \\
\hline \multicolumn{2}{|l|}{ Subunidade 1B - Comentando evidéneia(s) } \\
\hline \multicolumn{2}{|l|}{ Unidade retórica 5 - Conclusão(ốes) đa pesquisa } \\
\hline Subunidade 1A - Apresentando conclusâo(ðes) & e/ou \\
\hline \multicolumn{2}{|l|}{$\begin{array}{l}\text { Subunidade 1B - Relacionando hipótese(s) a resultado(s) } \\
\text { e/ou }\end{array}$} \\
\hline Subunidade 2 - Oferecendo/apontando contribuição(ões) & e/ou \\
\hline Subunidade 3 - Fazendo recomendação(Oes)/sugeståo(Oes) & \\
\hline
\end{tabular}

Fonte: Biasi-Rodrigues (1998, p. 113).

Como é usual na análise de movimentos retóricos, o quadro não implica que as cinco unidades retóricas estejam representadas em todos os textos analisados, tampouco na ordem descrita, considerando a coexistência de certa flexibilidade ao lado das regularidades nas convenções do gênero. $\mathrm{O}$ quadro representa, entretanto, a configuração retórica da maioria dos textos.

Biasi-Rodrigues (2009), fundamentada em estudos posteriores sobre resumos de teses, resumos de artigos de pesquisa e resumos de comunicações em eventos nas áreas disciplinares de linguística, educação, sociologia, economia, enfermagem, farmácia, engenharia elétrica e engenharia mecânica, argumenta que o conjunto dos resumos forma uma categoria de eventos comunicativos bem situados nas esferas comunicativas em que são realizados, apresentando marcas de prototipicidade e de restrições tanto em relação ao conteúdo quanto à forma. 
Uma alternativa de modelo descritivo da organização retórica de resumos foi proposta por Araújo (1999) ${ }^{5}$ após conduzir a análise de movimentos em um corpus de 12 textos produzidos por mestrandos da área de educação. A análise do corpus apontou para uma organização dos resumos em cinco moves (movimentos retóricos), os dois primeiros apresentando alternativas para sua construção, denominadas submoves).

FIGURA 3 - Organização retórica de resumos de dissertação em educação

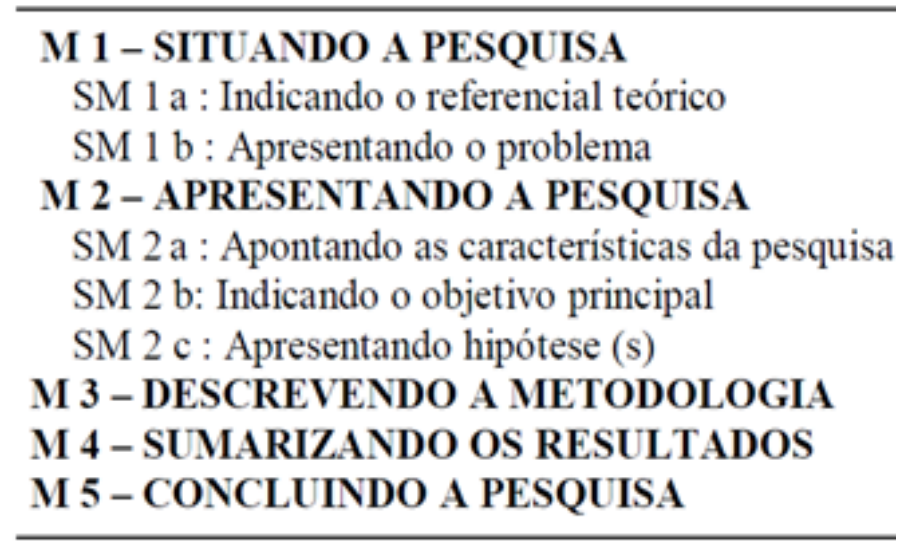

Fonte: Araújo (1999, p. 28).

Não sendo nosso propósito uma análise comparativa dos modelos de organização do resumo, apenas observamos, aqui, que o modelo de Araújo (1999) não prevê "subunidades" retóricas para realizar os movimentos dedicados a metodologia, resultados e discussão, como é o caso de BiasiRodrigues (1998). Como ambos os modelos se referem a resumos de dissertação de mestrado, uma questão para investigação posterior seria avaliar uma possível variação entre as áreas disciplinares de linguística e educação no que diz respeito à forma como cada uma constrói resumos. Entretanto, há que se considerar que o corpus analisado por Araújo (1999)é por demais restrito para permitir conclusões mais gerais.

Em estudo mais recente, Oliveira (2017) analisou um corpus de 60 resumos de comunicação oral em eventos na área de linguística. Apesar de

\footnotetext{
${ }^{5}$ Por sua vez, o modelo apresentado por Araújo (1999) retoma a proposta de Santos (1995) em análise de abstracts de artigos científicos, adaptando apenas o Move 5 (originalmente, "Discutindo a pesquisa").
} 
se tratar de uma variedade de resumo presumivelmente diferente daqueles investigados por Biasi-Rodrigues (1998) e por Araújo (1999), conforme peculiaridades já discutidas neste trabalho, os textos analisados pelo autor também indicaram uma organização retórica em cinco movimentos. As especificidades mais notáveis deste modelo consistem, em um primeiro olhar, na nomeação dos moves 1 e 2 , com seu foco no contexto e nos propósitos, respectivamente.

FIGURA 4 - Organização retórica de resumos de comunicação oral

\begin{tabular}{|l|}
\hline MOVE 1: ESTABELECER O CONTEXTO \\
\hline ER1: Contextualizando a pesquisa \\
\hline ER2: Apresentando o objeto de estudo \\
\hline ER3: Apresentando o problema a ser solucionado e/ou \\
\hline ER4: Levantando a hipótese \\
\hline MOVE 2: INTRODUZIR O PROPÓSITO \\
\hline ER1: Indicar a intenção do autor \\
\hline ER2: Apontando os objetivos \\
\hline MOVE 3: DESCREVER A METODOLOGIA \\
\hline ER1: Apresentando o quadro teórico-metodológico e/ou \\
\hline ER2: Descrição dos fundamentos teóricos \\
\hline ER3: Incluindo informações sobre o corpus \\
\hline ER4: Descrevendo os procedimentos ou métodos \\
\hline ER5: Indicando o escopo da pesquisa \\
\hline MOVE 4: SINTETIZAR OS RESULTADOS \\
\hline ER1: Apresentando os resultados \\
\hline MOVE 5: APRESENTAR AS CONCLUSÖES \\
\hline ER1: Apresentando as conclusões \\
\hline
\end{tabular}

Fonte: Oliveira (2017, p. 117).

Nos estudos de Biasi-Rodrigues (1998), Araújo (1999) e Oliveira (2017), nota-se uma flutuação terminológica na descrição da organização retórica dos resumos: enquanto Biasi-Rodrigues (1998) prefere usar o termo "unidade retórica" para descrever as estratégias retóricas principais, Araújo (1999) e Oliveira (2017) mantêm o termo move, originalmente usado por Swales (1990); quanto às estratégias mais específicas, que realizam os movimentos retóricos, Biasi-Rodrigues (1998) prefere "subunidades", enquanto Araújo (1999) fala de "submoves" e Oliveira (2017) se refere a “estratégias retóricas”. O termo original de Swales (1990), nesse caso, é step (passo). 
A variação terminológica, entretanto, não implica concepções distintas do fenômeno analisado pelos pesquisadores, nem divergência quanto ao marco teórico utilizado pelos três. Apesar das diferentes modalidades de resumo analisadas, bem como da diversidade de áreas de onde provêm, as unidades ou movimentos retóricos detectados por esses estudos são mais ou menos similares, apresentando variação bastante sutil, coerentemente com o conceito de colônia de gêneros. Essas evidências apontam para a relativa estabilidade e para uma organização prototípica do resumo acadêmico nas comunidades acadêmicas de diferentes áreas disciplinares. Entretanto, essa constatação não invalida, talvez até intensifique, a necessidade de um olhar atento para a variação, em especial considerando as demandas postas pelos processos de letramento acadêmico dos estudantes.

\section{O resumo no contexto do programa institucional de iniciação científica}

Para a compreensão do processo de letramentos acadêmicos dos alunos, bem como da inserção do gênero na organização das atividades no contexto acadêmico, é importante descrever como a instituição mantenedora do programa de IC orienta os estudantes sobre a inscrição de resumos para o evento. Desse ponto de vista, as diretrizes para produção do resumo podem ser vistas como exemplos de "metagênero", por seu papel de fornecer a "atmosfera ao redor dos gêneros", nas palavras de Giltrow (2002, p. 194). Metagêneros são "linguagem situada a respeito de linguagem situada".

Assim, o edital que normatizou as inscrições para o evento de divulgação das pesquisas de IC (p. 2) estabelece orientações acerca dos elementos que deviam constar nos resumos submetidos ao XVI Seminário de Iniciação Científica: “O resumo deverá conter brevemente: introdução, objetivos, métodos utilizados, resultados obtidos e conclusões”. Esses eram os elementos a serem contemplados nos resumos para que estes pudessem ser aceitos para apresentação no evento. Tais elementos aludem de forma muito próxima ao estabelecido pela Associação Brasileira de Normas Técnicas (ABNT) em sua NBR 6028 (2003, p. 2): “O resumo deve ressaltar o objetivo, o método, os resultados e as conclusões do documento”.

Tais elementos também são os propostos por Garcia (1992) e reproduzem a tradicional estrutura IMRD (introdução, metodologia, resultados e discussão). Fazendo uma busca rápida e aleatória nos editais de eventos de apresentação de pesquisas de IC de instituições de ensino 
superior, percebemos orientações similares às do edital supramencionado para a construção do resumo.

Assim, é esperado que o estudante vincule a construção de seu texto às orientações contidas do edital, buscando atender às expectativas institucionais que, por sua vez, de alguma forma representam as expectativas e convenções da comunidade acadêmica mais ampla. É importante enfatizar, novamente, que a produção do resumo sob a orientação do edital evidencia a inter-relação mantida pelos gêneros, descritível tanto em termos da relação entre um metagênero (edital) e o gênero resultante de suas diretrizes (resumo), como no sentido de que edital e resumo ocupam lugares privilegiados na cadeia de gêneros que organiza o programa de IC.

Comparando os movimentos retóricos propostos por Biasi-Rodrigues (1998), Araújo (1999) e Oliveira (2017) com os elementos recomendados no Edital PROP/UESPI 02/2017, percebemos similaridades, conforme pode ser observado no Quadro 1.

QUADRO 1 - Diferentes versões da organização retórica de resumos

\begin{tabular}{|l|l|l|l|}
\hline \multicolumn{1}{|c|}{$\begin{array}{c}\text { BIASI-RODRIGUES } \\
\mathbf{( 1 9 9 8 )}\end{array}$} & \multicolumn{1}{|c|}{ ARAÚJO (1999) } & \multicolumn{1}{|c|}{ OLIVEIRA (2017) } & $\begin{array}{l}\text { EDITAL PROP/ } \\
\text { UESPI 02/2017 }\end{array}$ \\
\hline Apresentação da pesquisa & Situando a pesquisa & Estabelecer o contexto & Introdução \\
\hline Contextualização da pesquisa & Apresentando a pesquisa & Introduzir o propósito & Objetivos \\
\hline Apresentação da Metodologia & Descrevendo a metodologia & Descrever a metodologia & Métodos utilizados \\
\hline Sumarização dos resultados & Sumarizando os resultados & Sintetizar os resultados & Resultados obtidos \\
\hline Conclusão da Pesquisa & Concluindo a pesquisa & Apresentar as conclusões & Conclusões \\
\hline
\end{tabular}

Fonte: elaboração própria.

A principal diferença entre os marcadores de condução da informação das pesquisas de Biasi-Rodrigues (1998), Araújo (1999) e Oliveira (2017) em relação ao que é solicitado nos resumos do Seminário de Iniciação Científica diz respeito à maneira esquemática como o resumo é descrito nas diretrizes do evento. No entanto, o edital do evento apresenta instruções complementares, por exemplo, para a introdução, determinando que nela se espera que os proponentes apresentem e contextualizem a pesquisa realizada. Já em relação aos objetivos, no modelo proposto pelo evento, há um item com recomendação específica e exclusiva para essa informação, que corresponde ao Move 2 de Oliveira (2017). 
O Seminário de Iniciação Científica é uma atividade acadêmica já consolidada na universidade e integra as atividades da comunidade acadêmica local há 15 anos. Dessa forma, é plausível afirmar que o evento participa de um contexto institucional específico em que os eventos de letramentos que dele fazem parte se materializam numa cadeia de gêneros bem definida. $\mathrm{Na}$ análise apresentada a seguir, consideramos que a apreensão (uptake) do gênero resumo se dá na sua relação com outros gêneros da cadeia estabelecida pelo Seminário de Iniciação Científica.

\section{Procedimentos metodológicos}

Neste estudo, foi analisado um corpus de 32 exemplares de resumos apresentados em um evento de IC de uma universidade pública nordestina. Os textos analisados constam no livro de resumos do seminário de IC em questão, tendo sido selecionados da grande área de Ciências Humanas, considerando que foi a que apresentou maior quantidade e diversidade de textos por áreas do conhecimento específicas. No mais, a seleção dos resumos se deu de forma aleatória.

Para analisar a configuração retórica dos textos, nos baseamos no modelo de Swales (1990) e, particularmente, na adaptação proposta por Biasi-Rodrigues (1998) para a análise de resumos. Além disso, após a caracterização da organização das informações nos exemplares de resumos, examinamos as pistas textuais e as informações coletadas via questionário para discutir aspectos do letramento acadêmico dos alunos autores dos resumos, apoiados em Lea e Street (2006) e Bezerra (2012a, 2015, 2017) e Bezerra e Lêdo (2018).

Complementando a análise textual, discutimos as respostas apresentadas pelos autores dos textos a um questionário aplicado via e-mail, cujas questões buscavam evidências das práticas letradas desses autores, bem como da relação destas com as práticas de letramentos realizadas em função das atividades relacionadas à iniciação científica.

\section{Os textos e o contexto no quadro dos letramentos acadêmicos dos alunos}

Neste tópico, apresentamos os resultados de nossas análises, primeiramente dos textos dos resumos e, em um segundo momento, das respostas ao questionário aplicado aos autores dos resumos. 


\subsection{A organização retórica dos resumos de pesquisas de iniciação científica}

O estudo criterioso da distribuição das informações nos textos dos resumos, tomando como parâmetro o modelo de análise proposto por Biasi-Rodrigues (1998), nos permitiu verificar as ocorrências dos respectivos movimentos retóricos, primeiro em termos quantitativos, para em seguida discutirmos como tais padrões de organização textual colaboram para a adequada condução das informações, sugerindo o desenvolvimento do processo de letramentos acadêmicos dos estudantes produtores dos resumos. No Gráfico 1, mostramos como as unidades estiveram representadas no corpus analisado.

GRÁFICO 1 - Unidades retóricas em resumos de pesquisas de IC

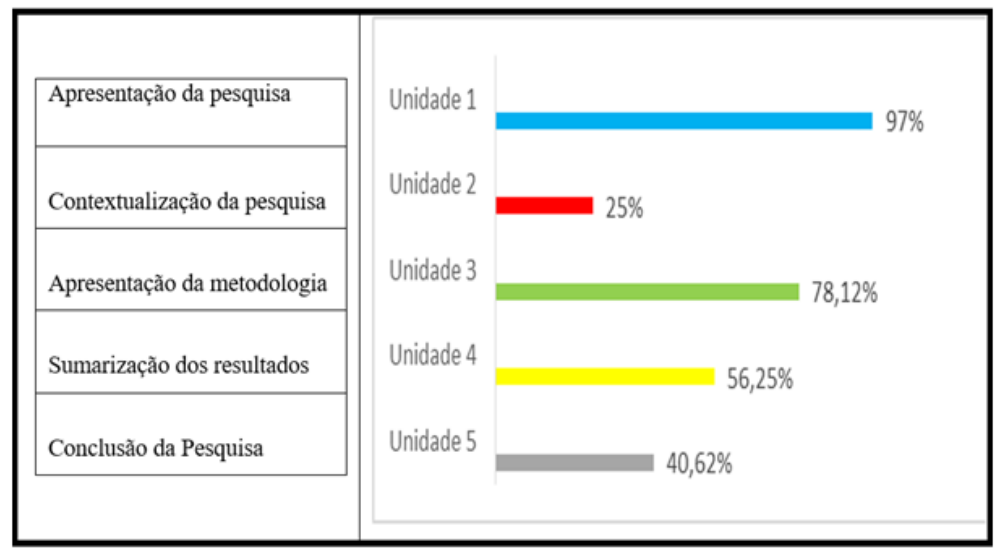

Fonte: elaboração própria.

Como mostra o quadro, a unidade retórica 1, dedicada à apresentação da pesquisa, é de longe a mais recorrente no corpus, com 97\% de ocorrências. Conforme Biasi-Rodrigues (1998), nessa unidade, o autor pode apresentar a pesquisa expondo o tópico principal, os objetivos ou as hipóteses. Em termos de recorrência, em segundo lugar aparece a unidade retórica 3, voltada para a apresentação da metodologia, com 78,12\%. Nessa unidade, o autor pode descrever os procedimentos da pesquisa, relacionar variáveis ou fatores de controle ou ainda citar ou descrever o método utilizado. A quarta e a quinta unidades retóricas, destinadas à apresentação de resultados e conclusões, são razoavelmente bem representadas no corpus, respectivamente com 56,25 e $40,62 \%$ cada. 
Um resultado surpreendente foi a realização em apenas $25 \%$ do corpus da unidade 2 , por meio da qual os autores poderiam contextualizar a pesquisa, quer indicando a área de conhecimento da pesquisa, quer citando teorias, modelos ou métodos anteriores ou, ainda, apresentando o problema que deu origem ao estudo, conforme as subunidades retóricas propostas por Biasi-Rodrigues (1998). A pouca representação desse movimento retórico nos textos sugere talvez uma incipiente familiaridade dos estudantes com a área em que estão se iniciando na pesquisa.

Refinando um pouco a análise, passamos a considerar as subunidades que compõem cada unidade retórica. Segundo o modelo de Swales (1990), essas subunidades ou steps são as estratégias retóricas que se apresentam aos autores para a realização do movimento retórico maior. Nesse momento da análise, não só mensuramos percentualmente a ocorrência de cada subunidade, como também observamos os pontos em que os dados não correspondem ao modelo de análise ou, vendo por outro ângulo, em que o modelo não dá conta dos dados. Assim, nossos dados revelaram duas estratégias retóricas não descritas no estudo de Biasi-Rodrigues (1998), as quais nomeamos como "justificando a pesquisa", subunidade 3 da unidade 1, e "apresentando/detalhando o corpus", subunidade 3 da unidade 3. O conjunto das subunidades retóricas verificadas no corpus se encontra no Gráfico 2.

GRÁFICO 2 - Subunidades retóricas em resumos de pesquisas de IC

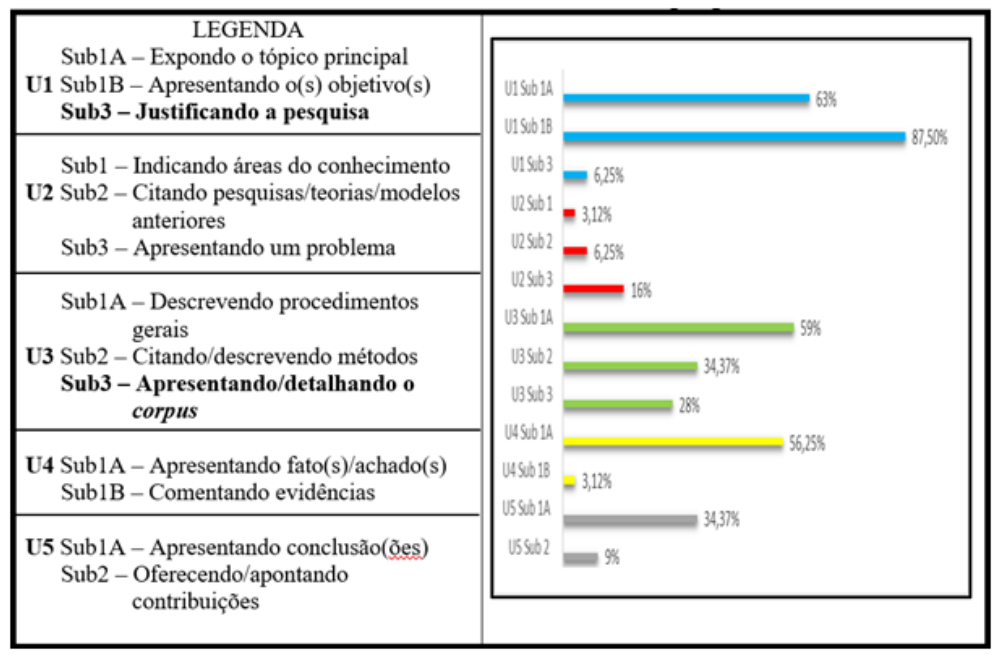

Fonte: elaboração própria. 
Como mostra o gráfico, nosso corpus, portanto, não confirma a ocorrência das seguintes subunidades, constantes no modelo de BiasiRodrigues (1998): apresentando as hipóteses, relacionando variáveis/ fatores de controle, relacionando hipóteses a resultados e fazendo recomendações/ sugestões. Por outro lado, encontramos duas subunidades não previstas pelo modelo, conforme já mencionado.

Para ilustrar os resultados, apresentamos um exemplar de resumo que compõe o corpus da pesquisa, analisado quanto às estratégias retóricas verificadas. Para facilitar a compreensão da análise, cada movimento é sinalizado por uma cor específica. Como se pode ver pelo ponto de interrogação acrescido à marcação "[U5-Sub1A]”, nem sempre é possível identificar com certeza a estratégia em questão apenas por meio da análise do texto do resumo.

\section{QUADRO 2 - Resumo de sociologia e respectivos movimentos retóricos}

Esta pesquisa tem como tema, trajetórias profissionais e ensino superior [U1-Sub1A] e objetiva analisar as características gerais da trajetória profissional de egressas e egressos do curso de Pedagogia do Campus Heróis do Jenipapo [U1-Sub1B] através de entrevistas em profundidade com dois egressos e quatro egressas, formados entre 2000 e 2016. [U3-Sub1A] A maioria dos egressos e egressas é parda, católica, solteira e está inserida no mercado de trabalho em sua área de formação, seja em instituições públicas ou privadas, seja em tempo integral ou parcial. A trajetória profissional do grupo é pautada na docência. [U3-Sub3] A ampliação da escolarização, permitindo a chegada ao ensino superior, é vista pelos sujeitos e sujeitas da pesquisa como um plano de carreira e investimento econômico e de tempo em estudo como parte do esforço para o crescimento profissional e melhoria das condições de vida. [U4-Sub1A] Isto se torna ainda relevante pelos limites tanto em termos de capital econômico, como de capital cultural enfrentados por esses sujeitos, limites que funcionaram como barreiras a serem superadas em suas trajetórias profissionais. [U5-Sub1A ?] Embora as pesquisadas e pesquisados considerem que a formação superior é teórica e necessita de mais prática no decorrer das disciplinas, e não apenas nos estágios, o curso de modo geral é bem avaliado, e aconselham outras pessoas a cursarem Pedagogia na instituição em que se graduaram. Embora a maioria dos entrevistados e entrevistadas atue na educação básica, a atuação no ensino superior é percebida como um mecanismo de melhoria das condições salariais, explicando assim, em parte, o prolongamento da escolarização. Os entrevistados e entrevistadas pretendem crescer na profissão, tanto em termos de titulação quanto de renda, o curso assume assim, um projeto de mobilidade social. Parte desta estratégia envolve, em todos os casos, o prolongamento das trajetórias escolares através de cursos de pós-graduação, lato e strictu sensu. [U4-Sub1A]
Apresenta a pesquisa expondo tópico e objetivo

Apresenta metodologia descrevendo procedimentos e detalhando participantes

Sumariza resultados apresentando achados

Apresenta conclusões da pesquisa (?)

Volta a sumarizar resultados apresentando achados

Fonte: elaboração própria. 
A estratégia de iniciar o texto apresentando a temática da pesquisa, seguida de seu objetivo, ilustrada pelo exemplo, foi utilizada com frequência pelos autores dos resumos. Várias características desse exemplo são também representativas da organização retórica do gênero resumo e servem para ilustrar a flexibilidade dos modelos de análise de movimentos retóricos. A primeira característica é a realização de mais de uma estratégia retórica na mesma unidade, como é o caso da unidade 1 , com as subunidades $1 \mathrm{~A}$ e $1 \mathrm{~B}$. A segunda característica é que nem todas as unidades são tratadas como obrigatórias, daí a ausência da unidade 2, que também foi a menos frequente em todo o corpus. Em terceiro lugar, unidades e subunidades retóricas podem ser "recicladas", conforme Swales (2004), e assim aparecer mais de uma vez no mesmo texto. Finalmente, as unidades e subunidades não ocorrem sempre na ordem expressa pelo modelo, que busca apenas captar as principais tendências. Assim, na análise proposta para o texto, a unidade 5 se acha intercalada na unidade 4 .

Esse texto, particularmente, apresenta mais um aspecto da análise que deve ser destacado, que é a ocorrência de um trecho não explicável pelas estratégias retóricas previstas no modelo adotado: "A maioria dos egressos e egressas é parda, católica, solteira e está inserida no mercado de trabalho em sua área de formação, seja em instituições públicas ou privadas, seja em tempo integral ou parcial. A trajetória profissional do grupo é pautada na docência." Esse trecho manifesta uma subunidade não descrita por BiasiRodrigues (1998), mas que esteve presente em quase um terço dos textos analisados (28\%). Nele é possível perceber que o autor descreve e caracteriza os participantes de sua pesquisa. É provável que esta seja uma marca da cultura disciplinar de subáreas de humanas que frequentemente lidam com pessoas na constituição de seus corpora. Assim, o resumo apresentado no Quadro 2 pode ser considerado como representativo de boa parte dos textos analisados.

A análise do corpus, no todo, nos permite chegar ao seguinte quadro descritivo da organização retórica de resumos de relatórios finais de pesquisas de iniciação científica, constituindo um modelo alternativo aos já existentes, para dar conta das peculiaridades de nosso objeto de estudo: 
QUADRO 3 - Organização retórica de resumos de pesquisas de IC em Ciências Humanas

\begin{tabular}{|ll|}
\hline Unidade retórica 1 - Apresentação da pesquisa & $\mathrm{e} / \mathrm{ou}$ \\
\hline $\begin{array}{l}\text { Subunidade 1 - Expondo o tópico principal } \\
\text { Subunidade 1 - Apresentando o(s) objetivo(s) } \\
\text { Subunidade 3 - Justificando a pesquisa }\end{array}$ & $\mathrm{e} / \mathrm{ou}$ \\
\hline Unidade retórica 2 - Contextualização da pesquisa & \\
\hline $\begin{array}{l}\text { Subunidade 1 - Indicando áreas do conhecimento } \\
\text { Subunidade 2 - Citando pesquisas/teorias/modelos anteriores }\end{array}$ & $\mathrm{e} / \mathrm{ou}$ \\
\begin{tabular}{l} 
Subunidade 3 - Apresentando um problema \\
\hline Unidade retórica 3 - Apresentação da metodologia
\end{tabular} & \\
\hline $\begin{array}{l}\text { Subunidade 1 - Descrevendo procedimentos gerais } \\
\text { Subunidade 2 - Citando/Descrevendo o(s) método(s) } \\
\text { Subunidade 3 - Apresentando/detalhando o corpus/os sujeitos }\end{array}$ & $\mathrm{e} / \mathrm{ou}$ \\
\hline Unidade retórica 4 - Sumarização dos resultados & $\mathrm{eu}$ \\
\hline Subunidade 1 - Apresentando fato(s) achado(s) \\
Subunidade 2 - Comentando evidências
\end{tabular}

Fonte: elaboração própria.

O esquema é representativo da organização retórica de resumos de pesquisas de IC, após a análise dos 32 resumos que constituem nosso corpus e que são provenientes de diferentes subáreas das Ciências Humanas. Em relação ao modelo proposto por Biasi-Rodrigues (1998), aqui vemos o acréscimo de duas novas subunidades, destacadas em itálico, e a exclusão das subunidades que não foram confirmadas por nossos dados.

\subsection{A produção de resumos no contexto dos letramentos acadêmicos dos alunos}

Como vem sendo discutido, os resumos que compõem o corpus deste estudo foram produzidos sob a orientação das práticas de letramento que envolvem o atendimento a um edital para a realização de um evento 
acadêmico de iniciação científica em cursos de graduação. Essas práticas envolvem diversas atividades de escrita que tanto antecedem como sucedem a produção do resumo.

Os dois editais que compõem a cadeia de gêneros do evento de IC são disponibilizados no site da instituição, sendo o primeiro deles direcionado aos docentes, que são os autores dos projetos de pesquisas submetidos à chamada pública. O segundo edital é mais direcionado aos alunospesquisadores do programa de IC, uma vez que são eles quem submete os resumos, cabendo ao docente orientador o papel de parecerista do trabalho submetido por cada orientando.

Enfim, essas práticas que constituem o contexto para a escrita do resumo se concretizam na forma de uma cadeia de gêneros, produzidos em sequência para que o evento afinal possa acontecer. O levantamento dos documentos (metagêneros) que normatizam a operacionalização do programa de IC resultou no seguinte delineamento da cadeia de gêneros.

FIGURA 5 - Cadeia de gêneros do evento acadêmico de iniciação científica

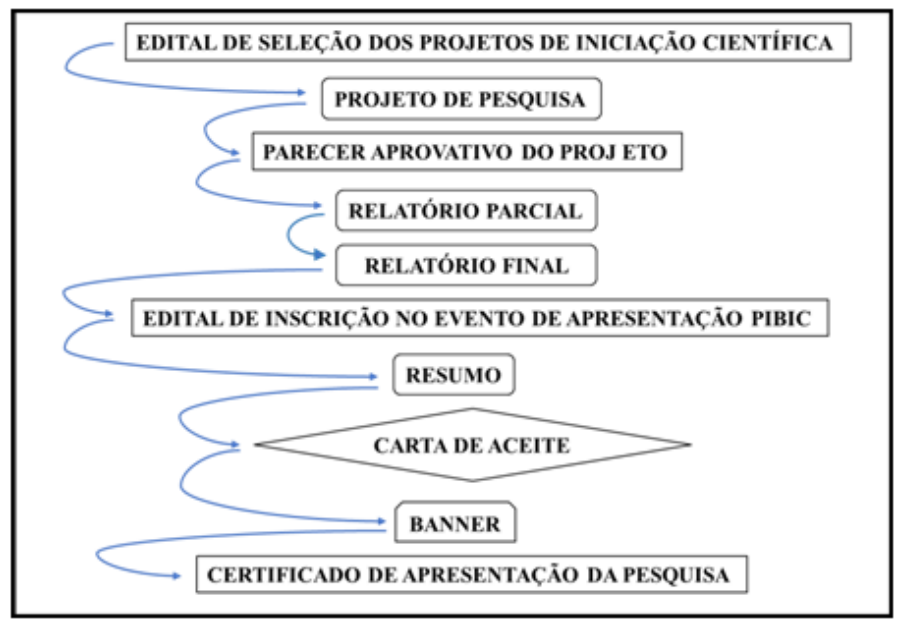

Fonte: elaboração própria.

Embora a explicitação da cadeia de gêneros lance bastante luz sobre as práticas de letramento subjacentes ao evento de IC, entre as quais se encontra a produção do resumo, cabe ainda ressaltar seu caráter esquemático e possivelmente lacunoso. Certamente há diversos e relevantes momentos de interação entre instituição, orientador e orientando que não são facilmente 
captados nessa descrição, inclusive devido ao recorte estabelecido para a pesquisa.

Alguns gêneros da cadeia, como o parecer, a carta de aceite e o certificado, podem ser caracterizados como "oclusos" ou "de suporte" (SWALES, 1996; SWALES; FEAK, 2009), por terem pouca visibilidade pública, ao contrário dos demais, que são mais acessíveis aos membros da comunidade discursiva. Para os fins deste estudo, nos interessa destacar principalmente a relação entre o resumo e o edital do evento, visto que no edital se estabelecem os elementos a serem contemplados nos resumos, porém a explicitação da cadeia possibilita localizar essa relação em um contexto mais amplo. Diante dessas considerações, vejamos como se posicionaram os alunos acerca do processo de produção dos resumos no enquadre dessas práticas de letramento.

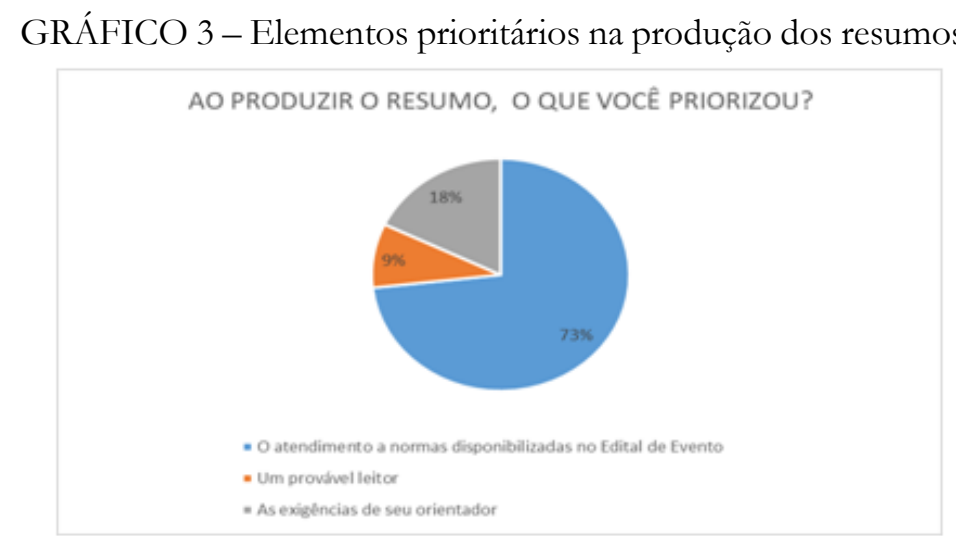

Fonte: elaboração própria.

Ao perguntarmos aos alunos sobre o que foi considerada prioridade na elaboração dos resumos, 73\% afirmaram atender às normas do Edital. Este número é um tanto emblemático por dois motivos principais: primeiro, esperava-se que todos ou quase todos atendessem às normas, sob pena de não terem os trabalhos aceitos; segundo, este número não corresponde adequadamente aos achados na análise dos dados. Conforme pode ser conferido no tópico anterior, a unidade retórica 5, por exemplo, está representada em pouco mais de $40 \%$ dos textos, o que significa que praticamente $60 \%$ dos textos não apresentam discussão dos resultados da pesquisa. Essa constatação leva a duas reflexões aparentemente paradoxais: primeira, sugere-se que a aprovação dos resumos, ao contrário do que está 
registrado no edital, não depende do atendimento rigoroso das exigências de conteúdo; segunda, o fato de um resumo não preencher um requisito do modelo de análise não implica que esse resumo apresenta algum tipo de deficiência retórica, uma vez que ele efetivamente cumpriu seus propósitos comunicativos ao ser aceito para o evento.

Outro aspecto a ser destacado diz respeito à pouca importância dada aos interlocutores pelos autores dos resumos. Somente $9 \%$ dos entrevistados consideraram prioridade o aspecto dialógico da comunicação. A impressão que temos é de que não têm consciência de que os resumos produzidos configuram mecanismos comunicativos típicos de uma comunidade discursiva, conforme Swales (2004), e que outros membros dessa comunidade irão interagir com tais textos, inclusive aqueles mais experientes, como os componentes do comitê científico e os avaliadores do evento.

Um segundo aspecto que foi questionado aos participantes da pesquisa dizia respeito a possíveis contatos prévios com o gênero, o que, a nosso ver, facilitaria a escrita dos seus próprios textos. Nesse sentido, grande parte dos estudantes declarou ter experiência de leitura de outros resumos antes de enfrentarem a tarefa de produzir um.

GRÁFICO 4 - Práticas de leitura de resumos

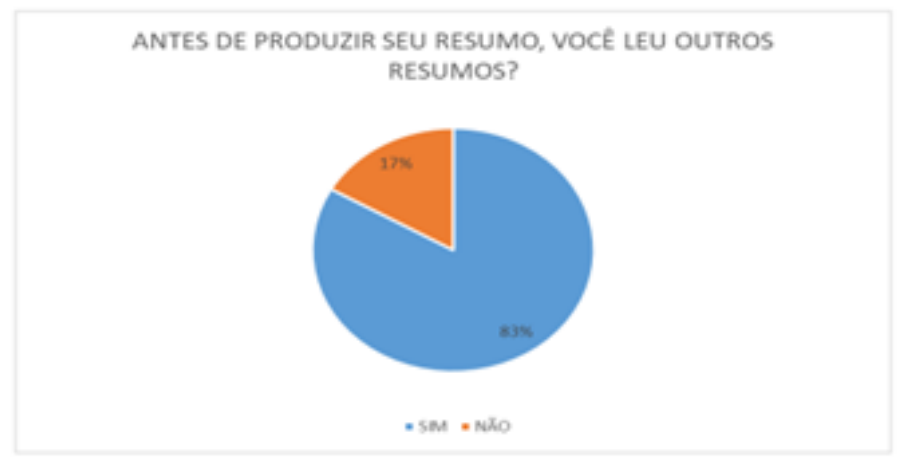

Fonte: elaboração própria.

O dado de que $87 \%$ dos alunos, antes de produzir seu resumo, teve contato com outros textos do gênero, é importante porque aponta para as práticas letradas dos estudantes. Certamente, o conjunto de nossa análise deixa claro que o mero conhecimento de outros resumos não é suficiente 
para a produção de um texto bem-sucedido no gênero, capaz de atender ao que é solicitado do edital e, portanto, esperado pela comunidade acadêmica.

Verificamos, ainda, que $67 \%$ dos participantes tiveram experiências anteriores ao evento com a escrita de resumo. Ao relacionarmos este dado com os percentuais de ocorrência das unidades retóricas presentes no Gráfico 1, concordamos com Oliveira (2017), ao defender o postulado de colônia de gêneros, em que a natureza e a construção do gênero tem nos propósitos comunicativos uma característica essencial que determina não apenas os diferentes gêneros, mas a variação entre gêneros assemelhados. Assim, é possível que os estudantes realmente tenham experiências anteriores de produção de resumos, mas não necessariamente em contexto comunicativo idêntico àquele posto pelo evento de IC.

GRÁFICO 5 - Práticas de escrita de resumos

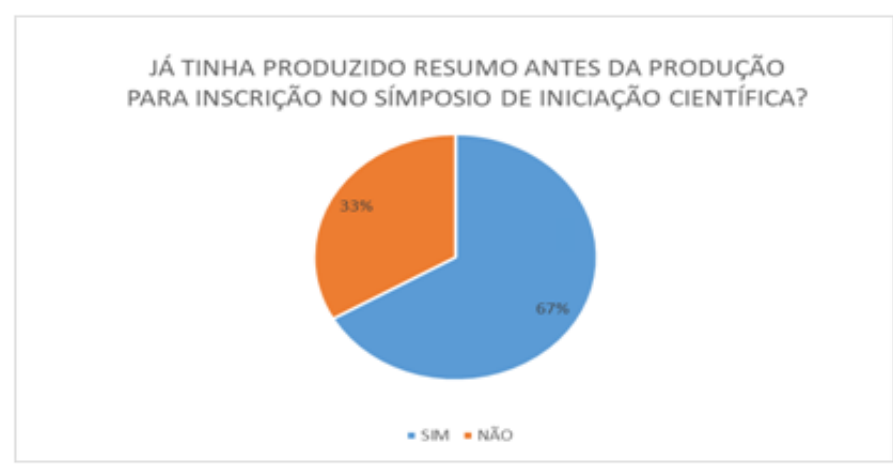

Fonte: elaboração própria.

Compreendemos a iniciação científica no contexto universitário como uma atividade que inicia o aluno de graduação na investigação e na produção de conhecimento, podendo contribuir para a efetivação das relações entre ensino e pesquisa, teoria e prática, graduação e pós-graduação, constituindose como um instrumento educativo que caminha entre a pesquisa e o ensino. Dentro desta perspectiva, solicitamos que os sujeitos opinassem sobre a importância da participação no programa de IC para o desenvolvimento de práticas de produção escrita de gêneros acadêmicos. O resultado segue abaixo: 
GRÁFICO 6 - Importância da vivência no PIBIC

para os letramentos acadêmicos

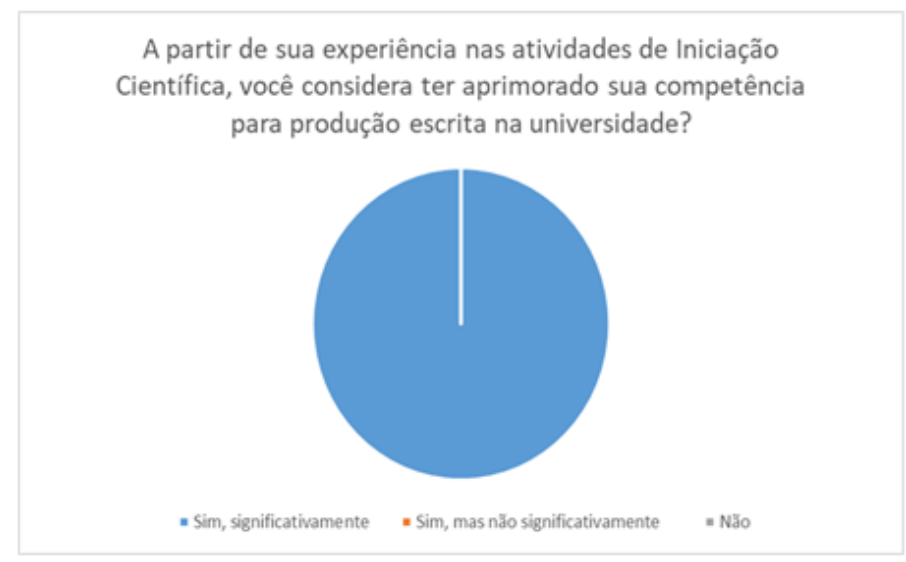

Fonte: elaboração própria.

Os alunos foram unânimes em responder que a participação em pesquisa de IC aprimorou sua competência para a prática de escrita na universidade. Este dado no leva a mencionar o pensamento de Freire (2003, p. 29):

Não há ensino sem pesquisa e pesquisa sem ensino. Esses que-fazeres se encontram um no corpo do outro. Enquanto ensino continuo buscando, reprocurando. Ensino porque busco, porque indaguei, porque indago e me indago. Pesquiso para constatar, constatando, intervenho, intervindo educo e me educo. Pesquiso para conhecer o que ainda não conheço e comunicar ou anunciar a novidade.

O pensamento freireano, apesar de tratar a pesquisa de forma um tanto geral, pode ser retomado no sentido de que os alunos egressos do programa, que responderam ao questionário, têm consciência de que vivenciar práticas de pesquisa contribui para o desenvolvimento dos letramentos, uma vez que o contexto em que estão inseridos leva à interação com a leitura e produção de gêneros acadêmicos, pois conforme o Mestre, pesquisar é também e sobretudo comunicar. 


\section{Considerações finais}

A análise dos textos aponta para variações significativas na organização e condução das informações nos resumos, o que pode dificultar a identificação de elementos considerados prototípicos do gênero. Para o contexto de produção dos textos analisados nesta pesquisa, um dos requisitos comunicativos é que o resumo contenha as informações principais do texto que o gerou (relatório final de pesquisa), para que o leitor tenha uma visão sintética de todo o trabalho e de sua estrutura, uma vez que o texto gerador do resumo não o acompanhará. Nesse sentido, a maioria dos alunos $(73 \%)$ afirmou ter levado em consideração o edital do evento ao produzir o resumo. Embora não esteja em perfeita harmonia com os dados quantitativos da descrição retórica dos textos, o elevado percentual sugere a compreensão dos alunos de que os textos se relacionam dentro de uma cadeia de gêneros.

Conforme verificamos em nossos dados, em relação aos aspectos retóricos e textuais, os resumos dos alunos mostraram uma organização retórica parcialmente diferente do previsto pelo modelo apresentado por Biasi-Rodrigues (1998). Mais especificamente, a diferença consistiu em duas subunidades retóricas recorrentes nos textos e não descritas no modelo utilizado, assim como em quatro subunidades que constam no modelo e não se confirmaram nos textos. Essas diferenças se traduzem no fato de que alguns textos mostraram lacunas em relação a elementos de conteúdo solicitados pelo edital do evento.

Entretanto, a sua aceitação sinaliza a realização bem-sucedida dos propósitos comunicativos do gênero, mesmo diante de eventual descumprimento de convenções formais. No contexto de produção em que os textos foram realizados, eles foram aceitos por membros mais experientes da comunidade discursiva (seus orientadores), portanto, atingiram seus propósitos comunicativos. As diferenças também reforçam e confirmam o aspecto teórico da flexibilidade e da relativa plasticidade dos gêneros, considerando as várias subáreas das graduações dos autores, bem como as práticas de letramento específicas em que estavam escrevendo.

Finalmente, resta refletir sobre o desempenho dos alunos na escrita dos resumos à luz dos letramentos acadêmicos. É sabido que o contexto em que os estudantes são chamados a escrever os resumos acadêmicos é marcado, por um lado, por relações assimétricas de poder; por outro lado, 
os estudantes representam exatamente os participantes da comunidade acadêmica em desvantagem nessa relação. Como participantes periféricos da academia, estudantes de graduação ensaiam os primeiros passos no sentido de desenvolver sua própria identidade e vê-la reconhecida pelos participantes mais experimentados.

Quanto a isso, tanto os textos, apresentados com sucesso à comissão organizadora do evento, como as informações prestadas via questionário sugerem que a participação em um programa de IC desempenha relevante papel em iniciar os alunos nos "mistérios" da escrita acadêmica (BARTHOLOMAE, 1985) e, portanto, contribui para o desenvolvimento de seus letramentos acadêmicos. Por um lado, ao final das respectivas pesquisas, eles foram capazes de atender, inclusive criativamente (com novas estratégias retóricas), às exigências da comunidade discursiva. Por outro lado, diferenças no uso de estratégias podem sugerir que ações como fazer recomendações ou sugestões na conclusão do resumo somente serão possíveis com o amadurecimento contínuo dos autores ao longo do referido processo de letramentos acadêmicos. O questionário, particularmente, mostra que esse processo não se limita ao cumprimento de normas especificadas em um edital, mas inclui um complexo repertório de práticas próprias das interações acadêmicas.

\section{Agradecimentos}

Este estudo contou com financiamento do CNPq através de bolsa de PósDoutorado Sênior (Chamada no 022/2018) concedida a um dos autores.

\section{Contribuição dos autores}

Todo o artigo foi escrito colaborativamente por ambos os autores, da versão inicial à final, a partir da análise inicial dos textos (resumos) e do questionário aplicado aos alunos pela primeira autora. Juntos, os autores aprofundaram a fundamentação teórica do trabalho, construíram o desenho metodológico, revisaram a análise dos dados e refletiram sobre as conclusões do estudo, de modo que o texto final reflete a dupla autoria, não sendo possível atribuir uma determinada seção a um ou a outro autor. 


\section{Referências}

ARAÚJO, A. D. Uma análise da organização discursiva de resumos na área de educação. Revista do GELNE, Fortaleza, v. 1, n. 1, p. 26-30, 1999.

ASSOCIAÇÃO BRASILEIRA DE NORMAS TÉCNICAS. NBR 6028: Informação e documentação - resumo - apresentação. Rio de Janeiro: ABNT, 2003.

BARTHOLOMAE, D. Inventing the University. In: ROSE, M. (ed.). When a Writer Can't Write: Studies in Writer's Block and Others Composing Process Problems. New York: Guilford Press, 1985. p. 273-285.

BAWARSHI, A.; REIFF, M. J. Gênero: história, teoria, pesquisa, ensino. São Paulo: Parábola Editorial, 2013.

BAZERMAN, C. A vida do gênero, a vida na sala de aula. In: . Gênero, agência e escrita. 2. ed. São Paulo: Cortez, 2011. p. 23-34.

BERKENKOTTER, C.; HUCKIN, T. N. Genre Knowledge in Disciplinary Communication: Cognition, Culture, Power. Hillsdale: LEA, 1995. DOI: https:// doi.org/10.2307/358302

BEZERRA, B. G. Gêneros no contexto brasileiro: questões (meta)teóricas e conceituais. São Paulo: Parábola Editorial, 2017.

BEZERRA, B. G. Letramentos acadêmicos e construção da identidade: a produção do artigo científico por alunos de graduação. Linguagem em (Dis)curso, Tubarão, SC, v. 15, n. 1, p. 61-76, jan./abr. 2015. DOI: https://doi.org/10.1590/1982-4017150104-1014

BEZERRA, B. G. Gêneros acadêmicos em cursos de especialização: conjunto ou colônia de gêneros? Revista Brasileira de Linguística Aplicada, Belo Horizonte, v. 12, n. 3, p. 443-461, 2012a. DOI: https://doi.org/10.1590/S1984-63982012000300002 BEZERRA, B. G. Letramentos acadêmicos na perspectiva dos gêneros textuais. Fórum Linguístico, Florianópolis, v. 9, n. 4, p. 247-258, out./dez. 2012b. DOI: https://doi.org/10.5007/1984-8412.2012v9n4p247

BEZERRA, B. G. Colônia de gêneros: o conceito e seu potencial analítico. In: SIMPÓSIO INTERNACIONAL DE ESTUDOS DE GÊNEROS TEXTUAIS, 4., 2007, Tubarão, SC. Anais [...] Tubarão, SC: Unisul, 2007. p. 715-728.

BEZERRA, B. G.; LÊDO, A. C. O. Gêneros acadêmicos e processos de letramento no ensino superior. In: PEREIRA, R. C. M. (org.). Escrita na universidade: panoramas e desafios na América Latina. João Pessoa: Ed. da UFPB, 2018. p. 173-205. 
BHATIA, V. K. Análise de gêneros hoje. In: BEZERRA, B. G.; BIASIRODRIGUES, B.; CAVALCANTE, M. M. (org.). Gêneros e sequências textuais. Recife: EDUPE, 2009. p. 159-195.

BHATIA, V. K. Worlds of Written Discourse: A Genre-Based View. London: Continuum, 2004.

BIASI-RODRIGUES, B. O gênero resumo: uma prática discursiva na comunidade acadêmica. In: BIASI-RODRIGUES, B.; ARAÚJO, J. C.; SOUSA, S. C. T. (org.). Gêneros textuais e comunidades discursivas: um diálogo com John Swales. Belo Horizonte: Autêntica, 2009. p. 49-75.

BIASI-RODRIGUES, B. Estratégias de condução de informações em resumos de dissertações. 1998. 307f. Tese (Doutorado em Linguística) - Universidade Federal de Santa Catarina, Florianópolis, 1998.

FREIRE, P. Pedagogia da autonomia: saberes necessários à prática docente. São Paulo: Paz e Terra, 2003.

GARCIA, O. M. Comunicação em prosa moderna. 15. ed. Rio de Janeiro: Editora Fundação Getúlio Vargas, 1992.

GILTROW, J. Meta-genre. In: COE, R.; LINGARD, L.; TESLENKO, T. (ed.). The Rhetoric and Ideology of Genre. Cresskill: Hampton Press, 2002. p. 187-205.

LEA, M. R.; STREET, B. V. The "Academic Literacies" Model: Theory and Applications. Theory Into Practice, Oxfordshire, v. 45, n. 4, p. 368-377, 2006. DOI: https://doi.org/10.1207/s15430421tip4504_11

LEA, M. R.; STREET, B. V. Student Writing in Higher Education: An Academic Literacies Approach. Studies in Higher Education, Oxfordshire, v. 23, n. 2, p. 157-172, 1998. DOI: https://doi.org/10.1080/03075079812331380364

MILLER, C. R. Gênero como ação social. In: Gênero textual, agência e tecnologia. São Paulo: Parábola Editorial; Recife: Ed. Universitária da UFPE, 2012. p. 21-44.

OLIVEIRA, J. H. P. de. Análise de gênero em contextos específicos: organização retórica e construção de sentidos no resumo de comunicação para eventos acadêmicos. 2017. 198f. Dissertação (Mestrado em Ciências da Linguagem) - Universidade Católica de Pernambuco, Recife, 2017.

PIMENTEL, R. L. Um estudo sobre hibridização e agrupamento de gêneros no Facebook. 2014. 118f. Dissertação (Mestrado em Linguística) - Universidade Federal de Pernambuco, Recife, 2014. 
RUSSELL, D. R.; LEA, M.; PARKER, J.; STREET, B. V.; DONAHUE, T. Exploring Notions of Genre in "Academic Literacies" and "Writing across the Curriculum": Approaches across Countries and Contexts. In: BAZERMAN, C.; BONINI, A.; FIGUEIREDO, D. (ed.). Genre in a Changing World. Fort Collins: The WAC Clearinghouse; West Lafayette: Parlor, 2009. p. 395-423. DOI: https://doi. org/10.37514/PER-B.2009.2324.2.20

STREET, B. V. Letramentos sociais: abordagens críticas do letramento no desenvolvimento, na etnografia e na educação. Tradução de Marcos Bagno. São Paulo: Parábola Editorial, 2014.

STREET, B. V. Eventos de letramento e práticas de letramento. In: MAGALHÃES, I. (org.). Discursos e práticas de letramento: pesquisa etnográfica e formação de professores. Campinas: Mercado de Letras, 2012. p. 69-92.

STREET, B. V. Os novos estudos sobre letramento: histórico e perspectivas. In: MARINHO, M.; CARVALHO, G. T. (org.). Cultura escrita e letramento. Belo Horizonte: Ed. UFMG, 2010. p. 33-53.

SWALES, J. M. Research Genres: Exploration and Applications. Cambridge: Cambridge University Press, 2004. DOI: https://doi.org/10.1017/CBO9781139524827

SWALES, J. M. Genre Analysis: English in Academic and Research Settings. Cambridge: Cambridge University Press, 1990.

SWALES, J. M. Occluded Genres in the Academy: The Case of the Submission Letter. In: VENTOLA, E.; MAURANEN, A. (ed.). Academic Writing: Intercultural e Textual Issues. Amsterdam: John Benjamins, 1996. p. 45-58. DOI: https://doi. org/10.1075/pbns.41.06swa

SWALES, J. M.; FEAK, C. B. Abstracts and the Writing of Abstracts. Michigan: The University of Michigan Press, 2009. DOI: https://doi.org/10.3998/mpub.309332

Data de submissão: 27/05/2020. Data de aprovação: 19/12/2020. 